\title{
Refractory hypercalcaemia secondary to parathyroid carcinoma: response to high-dose denosumab
}

\author{
Dharshini Karuppiah', Gaya Thanabalasingham ${ }^{1}$, Brian Shine², Lai Mun Wang ${ }^{3}$, \\ Gregory P Sadler ${ }^{\mathbf{4}}$, Niki Karavitaki ${ }^{1}$ and Ashley B Grossman ${ }^{\mathbf{1}}$ \\ Departments of ${ }^{1}$ Endocrinology, ${ }^{2}$ Chemical Pathology, ${ }^{3}$ Cellular Pathology and ${ }^{4}$ Endocrine Surgery, \\ Oxford Centre for Diabetes, Endocrinology and Metabolism (OCDEM), University of Oxford, Churchill Hospital, \\ Oxford OX3 7LE, UK
}

Correspondence should be addressed to A B Grossman Email ashley.grossman@ ocdem.ox.ac.uk

\begin{abstract}
Objective: Hypercalcaemia is an important cause of increased morbidity and mortality in patients with parathyroid carcinoma. Surgical resection is the mainstay of treatment but, equally, managing hypercalcaemia is of paramount importance. At present, few therapies have been shown to be effective in the most severe cases. This report describes the efficacy of denosumab in a patient with parathyroid carcinoma when conventional therapies had been shown to be relatively ineffective.

Subject, methods and results: A 50-year-old man presented with symptomatic hypercalcaemia 1 year after the surgery for his parathyroid carcinoma. Investigations revealed raised serum calcium and parathyroid hormone concentrations consistent with the recurrence of the disease. Imaging failed to localise any surgically remediable foci. Medical management with loop diuretics, calcimimetics and bisphosphonates failed to provide a sustained response. Denosumab, as a monthly injection, led to a gradual decrement in his peak calcium concentrations with the values now persistently below $3 \mathrm{mmol} / \mathrm{l}$. Conclusions: Denosumab, a fully human MAB that binds to the 'receptor activator of nuclear factor $K B$ ligand (RANKL)', was shown to have a profound effect in modulating malignant hypercalcaemia. This medication should be considered as an effective option in patients with refractory hypercalcaemia secondary to parathyroid carcinoma.
\end{abstract}

\section{Introduction}

Parathyroid carcinoma is a rare disease, which occurs in $<1 \%$ of all cases of hyperparathyroidism (1). Although it is difficult to distinguish between parathyroid adenoma and carcinoma clinically, parathyroid carcinoma is usually associated with profound hypercalcaemia and very high parathyroid hormone (PTH) concentrations. Compared with its benign counterpart, a palpable neck mass and concomitant renal and skeletal diseases are more common among patients with parathyroid carcinoma. A high degree of clinical suspicion is necessary in order to optimise the surgical outcome, as the first operation is the most important one: this should involve an en bloc resection of the tumour as well as all potential areas of invasion at the initial operation (2). While parathyroid carcinoma has a relatively low potential for distant metastasis, it does tend to recur locally. These tumours may be very indolent, even when metastatic, and patients rarely die from tumour per se. It is therefore of paramount importance to control the hypercalcaemia, which may be lethal (3). However, at present, few therapies have been shown to be effective in the most severe cases.

Cinacalcet, a calcimimetic agent, has been used in these patients: under normal circumstances, PTH secretion is regulated by the calcium-sensing receptor on parathyroid chief cells and cinacalcet lowers PTH concentrations by increasing the sensitivity of these receptors. 
It has been used to control the hypercalcaemia in parathyroid carcinoma, but its effectiveness in this situation depends on the tumour expressing the receptors, which may not always be the case. Furthermore, cinacalcet is often poorly tolerated at doses required for control (4). Bisphosphonates have shown some promise in the treatment of hypercalcaemia by inhibiting PTHdependent osteoclast activation; pamidronate and zoledronate are widely used for such patients, although renal function needs to be monitored periodically (5).

Denosumab is a fully human MAB that binds to the 'receptor activator of nuclear factor $\kappa \mathrm{B}$ ligand (RANKL)' and inhibits osteoclast development, activation and survival. It has been shown to have a profound effect in modulating malignant hypercalcaemia (6). Very recently, the use of denosumab in the treatment of hypercalcaemia related to parathyroid carcinoma has been reported in two case reports $(7,8)$. We were contemporaneously using denosumab for a similar patient with hypercalcaemia and parathyroid carcinoma and report its high efficacy when all else had failed.

\section{Case presentation}

A 50-year-old man was referred to the Endocrine Department with a recurrence of symptomatic hypercalcaemia. Two years earlier, he had been referred to a renal physician with subacute deterioration in his renal function. He had a history of significant weight loss, malaise, constipation and arthralgia. There was no radiation exposure or personal history of cancer. He had a family history of bowel cancer in his mother and sister, who had died at the age of 68 and 46 years respectively. One of his other sisters died from melanoma in her early 20 s. On further investigation of his impaired renal function, he was found to have an elevated serum calcium concentration of $3.70 \mathrm{mmol} / \mathrm{l}$ (normal range $2.12-2.62 \mathrm{mmol} / \mathrm{l}$ : all values are 'albumin-adjusted' serum calcium concentrations) with a serum PTH concentration of $177 \mathrm{pmol} / \mathrm{l}$ (normal range $1.3-7.6 \mathrm{pmol} / \mathrm{l})$. Plain radiography of his chest revealed a symmetrical periosteal reaction and subperiosteal bone resorption involving the distal clavicles, and he had medullary nephrocalcinosis on renal ultrasonography. A radiolabelled ${ }^{99} \mathrm{Tm}$-sestamibi scan and neck ultrasonography both localised a left parathyroid tumour. The very high PTH concentration and markedly elevated calcium concentration with concomitant renal and bone involvement raised the suspicion of a parathyroid carcinoma. He was scheduled for emergency surgery for left thyroid lobectomy, parathyroidectomy and central node dissection. At operation, a large mediastinal tumour measuring $\sim 3.0 \times 2.2 \times 1.5 \mathrm{~cm}$ was found, requiring median sternotomy. Histology of the mediastinal mass consisted of a mixed population of cells, the majority of which resembled parathyroid chief cells with a smaller proportion of oncocytic cells. There were areas of necrosis and mitoses, and the lesion had an infiltrative margin (Fig. 1). In these infiltrative areas, the tumour looked frankly malignant, and there were foci suspicious of lymphovascular invasion. Overall, the tumour was suggestive of a parathyroid carcinoma, and at one edge, there remained a small area of convincing parathyroid tissue that had retained its original architecture. Immunohistochemistry showed patchy positivity with chromogranin and negativity for CEA, calcitonin, TTF1 and thyroglobulin. The tumour itself was negative for parafibromin staining (Fig. 2), confirming its status as a parathyroid carcinoma. The thyroid lobe showed no evidence of malignancy, while a small nodule adjacent to the thyroid was consistent with parathyroid tissue hyperplasia. Postoperatively, his staging imaging investigations were negative, including normal magnetic resonance imaging (MRI) of the neck and computed tomography (CT) scanning of the chest, abdomen and pelvis. Post-operatively, serum PTH concentrations dropped to $0.3 \mathrm{pmol} / 1$ immediately.
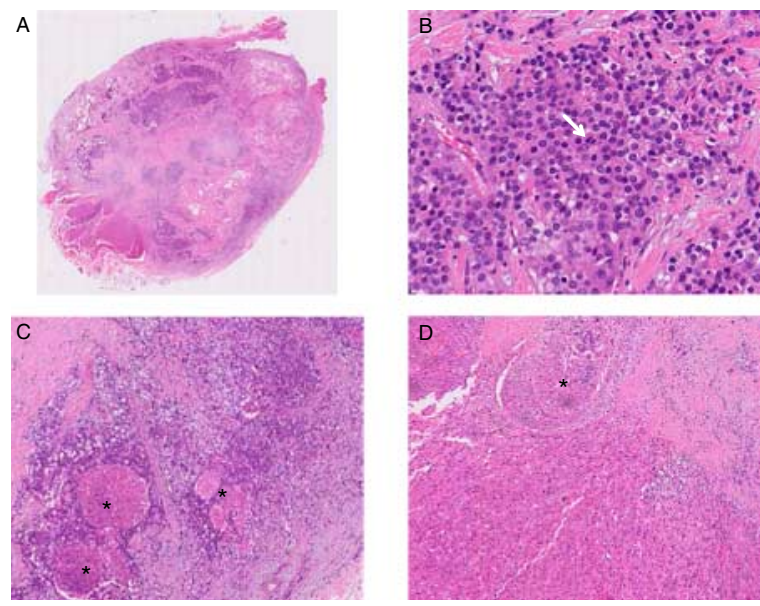

\section{Figure 1}

Parathyroid carcinoma. (A) Low image scan of H\&E section showing circumscribed tumour with broad bands of fibrosis. (B) Tumour cells with an abnormal mitotic figure $(200 \times)$ are indicated by the white arrow. The tumour is composed of lobules of chief cells $(C, 40 \times)$ and oncocytes $(D, 40 \times)$ with foci of necrosis $\left(^{*}\right)$. Immunohistochemical studies show chromogranin positivity, confirming its endocrine nature. Full colour version of this figure available via http://dx.doi.org/10.1530/EJE-14-0166. 


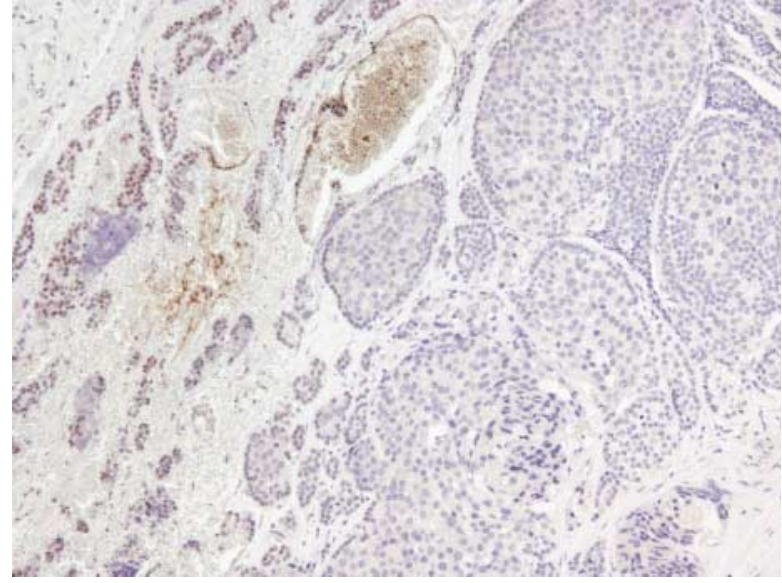

\section{Figure 2}

Parafibromin immunohistochemistry showing positive nuclear staining in the residual normal parathyroid gland tissue (left) with absent nuclear immunoreactivity in the malignant tumour cells (right). Full colour version of this figure available via http://dx.doi.org/10.1530/EJE-14-0166.

The levels had risen to $34.7 \mathrm{pmol} / 1$ at 1 month, but gradually showed a trend downwards to $20.2 \mathrm{pmol} / \mathrm{l}$ at 2 months and $8.2 \mathrm{pmol} / \mathrm{l}$ at 8 months after the surgery. His calcium concentration was $2.93 \mathrm{mmol} / \mathrm{l}$ immediately after surgery and dropped to $2.16 \mathrm{mmol} / \mathrm{l}$ at 1 month, which raised the possibility of hungry bone disease. He was commenced on vitamin D and calcium supplements, but this was stopped after 2 months when the calcium concentration was $2.45 \mathrm{mmol} / \mathrm{l}$. He was asymptomatic with normocalcaemia for 8 months before his new presentation. Germline genetic testing was negative for any pathological variants in MEN1, CDC73 (the parafibromin gene), CASR, CDKN1A, CDKN1B, CDKN2B, $C D K N 2 C$ and $R E T$ oncogenes. Multiplex ligationdependent probe amplification analysis (MPLA) of MEN1 and CDC73 did not show any deletion or duplication.

At presentation in our department, investigation revealed an elevated serum calcium concentration of $3.34 \mathrm{mmol} / \mathrm{l}$ and a PTH concentration of $73 \mathrm{pmol} / \mathrm{l}$, suggesting recurrence of his parathyroid carcinoma. MRI scanning of his neck did not show any evidence of local recurrence, while FDG-positron emission tomography (PET)/CT and ${ }^{99} \mathrm{Tm}$-sestamibi scanning also failed to localise surgically resectable lesions.

As there was no surgically remediable focus of the disease, we opted for medical management of his hypercalcaemia. He was commenced on cinacalcet at a dose of $30 \mathrm{mg}$ daily, the dose being gradually increased. Unfortunately, due to gastrointestinal side effects he was unable to tolerate a dose above $30 \mathrm{mg}$ daily, on which his calcium concentration remained elevated at $3.6 \mathrm{mmol} / \mathrm{l}$. At this point, he was admitted in hypercalcaemic crisis with a very high calcium concentration of $4.2 \mathrm{mmol} / \mathrm{l}$ : he was managed with fluids and i.v. bisphosphonates, initially pamidronate at a dose of $60 \mathrm{mg}$ and then zoledronate at a dose of $5 \mathrm{mg}$. Following the treatment with zoledronate, his calcium concentration fell to $2.38 \mathrm{mmol} / \mathrm{l}$ but returned to $2.92 \mathrm{mmol} / \mathrm{l}$ at 6 days and to $3.54 \mathrm{mmol} / \mathrm{l}$ at 23 days after the infusion. Given the patient's failure to respond in a sustained manner to the above measures, we then trialled denosumab at a dose of $60 \mathrm{mg}$ subcutaneously as a single dose, after consultation with the Chairman of the Hospital Drugs Committee.

His serum calcium concentrations decreased from 3.54 to $2.93 \mathrm{mmol} / \mathrm{l}$ at 10 days following the first dose of denosumab. However, by 4 weeks, it had risen to $3.38 \mathrm{mmol} / \mathrm{l}: 4$ weeks later he received his second dose of denosumab $60 \mathrm{mg}$. This lowered his calcium concentration to $2.93 \mathrm{mmol} / \mathrm{l}$. Following an application for an 'Individual Funding Requirement' from the local area Clinical Commissioning Group (CCG), in accord with UK NHS regulations, permission was obtained to continue treatment with denosumab. He was thereafter treated with denosumab at a dose of $120 \mathrm{mg}$ subcutaneously every 4 weeks with a fall following each injection and then a return to an elevated level, but the peak calcium concentration gradually decreased (see Fig. 3). He remains on 4-weekly denosumab at a dose of $120 \mathrm{mg}$ with serum calcium concentration persistently below $3 \mathrm{mmol} / \mathrm{l}$. His PTH concentrations remain persistently elevated and are trending upwards; this may reflect the decreased feedback inhibition of serum calcium that has concomitantly declined with treatment, but we suspect this is mainly a progression of his carcinoma.

\section{Discussion}

Parathyroid carcinoma is a rare disease: evidence to guide optimal treatment is therefore scarce. Surgical resection of the tumour is the mainstay of treatment, but more than two-thirds of patients will show recurrence after the initial operation. Adjuvant radiotherapy may play a role in the post-operative setting, but parathyroid carcinoma is generally resistant to radiation therapy (9). The published literature on medical therapy is limited due to the rarity of the disease, and there are no generally accepted regimens with proven efficacy using cytotoxic chemotherapy. 


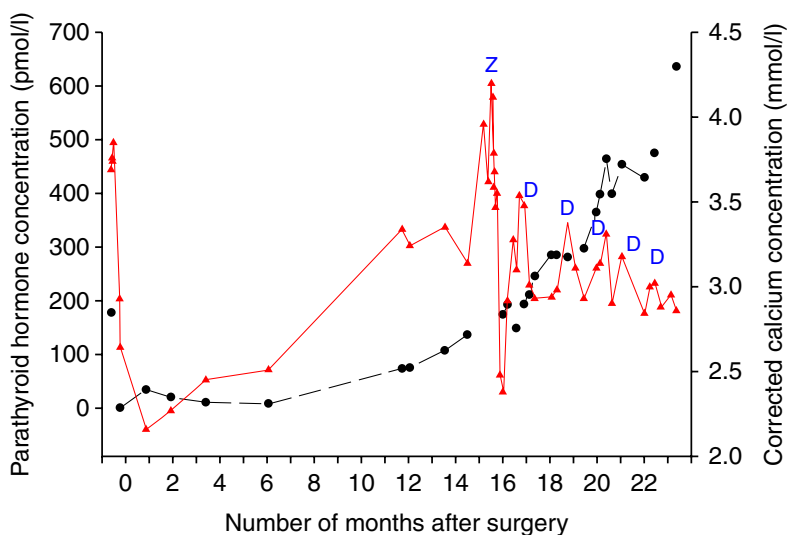

\section{Figure 3}

This graph illustrates the patient's calcium (solid line, closed triangles - scale on the right axis) and parathyroid hormone concentrations (interrupted line, closed circles - scale on the left axis) plotted against duration in months after surgery. This emphasises the relentless increase in PTH concentrations 12 months following surgery. In this graph, zoledronate ( $Z$ ) follows an inpatient admission with severe hypercalcaemia (corrected calcium concentration $>4 \mathrm{mmol} / \mathrm{l}$ ), which was treated with aggressive i.v. fluids, furosemide and finally i.v. zoledronate (denoted as $\mathrm{Z}$ ). This led to an impressive but short-lived drop in calcium ( $<4$ weeks). Denosumab (denoted by $D$ ) was then given, first two doses at $60 \mathrm{mg}$ s.c. and then $120 \mathrm{mg}$ s.c. This led to gradual decrement in the peak calcium concentrations. Full colour version of this figure available via http://dx.doi.org/10.1530/EJE-14-0166.

Medical therapy is thus primarily focused on managing the hypercalcaemia, although this is often severe and may be highly resistant to conventional treatments, and is usually the cause of death in patients with metastatic disease. Calcimimetics and bisphosphonates have been used in controlling the hypercalcaemia, but with limited effectiveness, and calcitonin and octreotide use has also been reported in a few case reports (2). Rapid improvement in symptoms and calcium concentrations following immunisation with human and bovine PTH peptides was reported in one case (10), but this therapy is complex and not generally available.

Denosumab is a novel inhibitor of osteoclast function that is approved in many countries for the treatment of post-menopausal women with osteoporosis, for patients at a high risk for fracture, for the prevention of skeletalrelated events in patients with bone metastases from solid tumours and unresectable giant cell tumours (11).
Two randomised trials have demonstrated a higher rate of hypocalcaemia with denosumab compared with zoledronic acid in patients with advanced malignancies $(12,13)$. Managing refractory hypercalcaemia remains a great challenge in patients with parathyroid carcinoma, and we report our experience in managing a patient with refractory hypercalcaemia due to parathyroid carcinoma using denosumab. Currently, the patient has his severe hypercalcaemia regulated to less critical levels by monthly s.c. injections of denosumab with no adverse events, and we may be able to space out his injections to longer intervals. We confirm recent case reports that denosumab should be considered as an option for this rare disease. In addition to its potent hypocalcaemic effect, it has other advantages: compared with bisphosphonates, it does not require dose adjustment in renal impairment and it is administered subcutaneously rather than intravenously. However, whether this response will be maintained over the long term remains to be seen.

\section{Declaration of interest}

The authors declare that there is no conflict of interest that could be perceived as prejudicing the impartiality of the research reported. The patient was fully informed about the medication and possible adverse effects and written consent was obtained before initiating this treatment. The patient has consented to the publication of his data.

\section{Funding}

This research did not receive any specific grant from any funding agency in the public, commercial or not-for-profit sector.

\section{References}

1 Mittendorf EA, McHenry CR \& Christopher R. Parathyroid carcinoma Journal of Surgical Oncology 200589 136-142. (doi:10.1002/jso.20182)

2 Shane E. Parathyroid carcinoma. Journal of Clinical Endocrinology and Metabolism 200186 485-493. (doi:10.1210/jcem.86.2.7207)

3 Busaidy NL, Jimenez C, Habra MA, Schultz PN, El-Naggar AK, Clayman GL, Asper JA, Diaz EM Jr, Evans DB, Gagel RF et al. Parathyroid carcinoma: a 22-year experience. Head \& Neck 200426 716-726. (doi:10.1002/hed.20049)

4 Silverberg SJ, Rubin MR, Faiman C, Peacock M, Shoback DM, Smallridge RC, Schwanauer LE, Olson KA, Klassen P \& Bilezikian JP. Cinacalcet hydrochloride reduces the serum calcium concentration in inoperable parathyroid carcinoma. Journal of Clinical Endocrinology and Metabolism 200792 3803-3808. (doi:10.1210/jc.2007-0585)

5 Lumachi F, Stefano MM \& Basso U. Parathyroid cancer: etiology, clinical presentation and treatment. Anticancer Research 200626 4803-4808.

6 Fizazi K, Carducci M, Smith M, Damião R, Brown J, Karsh L, Milecki P, Shore N, Rader M, Wang H et al. Denosumab versus zoledronic acid for treatment of bone metastases in men with castration-resistant prostate cancer: a randomised, double-blind study. Lancet 2011377 813-822. (doi:10.1016/S0140-6736(10)62344-6) 
7 Vellanki P, Lange K, Elaraj D, Kopp PA \& El Muayed M. Denosumab for management of parathyroid carcinoma mediated hypercalcaemia. Journal of Clinical Endocrinology and Metabolism 201499 387-390. (doi:10.1210/jc.2013-3031)

8 Samantha EB, Alison MW, David TR \& John AD. Resistant hypercalcaemia in metastatic parathyroid carcinoma. Medical Journal of Australia 2013198 559-561. (doi:10.5694/mja12.11243)

9 Lawrence Kim, Parathyroid carcinoma. Medscape 2013. updated 11th September 2013. http://emedicine.medscape.com/article/280908overview

10 Bradwell AR \& Harvey TC. Control of hypercalcaemia of parathyroid carcinoma by immunization. Lancet 1999353 370-373. (doi:10.1016/ S0140-6736(98)06469-1)
11 FDA approval for denosumab. National Cancer Institute 2013. updated 7th February 2013. www.cancer.gov/cancertopics/druginfo/fdadenosumab

12 Boikos SA \& Hammers HJ. Denosumab in the treatment of bisphosphonate-refractory hypercalcaemia. Journal of Clinical Oncology 201230 e299. (doi:10.1200/JCO.2012.41.7923)

13 Henry DH, Costa L, Goldwasser F, Hirsh V, Hungria V, Prausova J, Scagliotti GV, Sleeboom H, Spencer A, Vadhan-Raj S et al. Randomized, double-blind study of denosumab vs zoledronic acid in the treatment of bone metastases in patients with advanced cancer (excluding breast and prostate cancer) or multiple myeloma. Journal of Clinical Oncology 201129 1125-1132. (doi:10.1200/JCO.2010. 31.3304)

Received 26 February 2014

Revised version received 9 April 2014

Accepted 15 April 2014 